\title{
Characteristics of severe acute respiratory infection- associated hospitalization in Yemen, 2014/15
}

A.A.K. Thabet ${ }^{1}$, A. Al-Kohani ${ }^{2}$, A. Shadoul ${ }^{3}$, A. Al-Mahaqri ${ }^{4}$, M. bin Yahya ${ }^{5}$, A.H. Saleh ${ }^{6}$, D. Al-Adeemy ${ }^{7}$, W. Khan $^{8}$ and M. Malik ${ }^{8}$

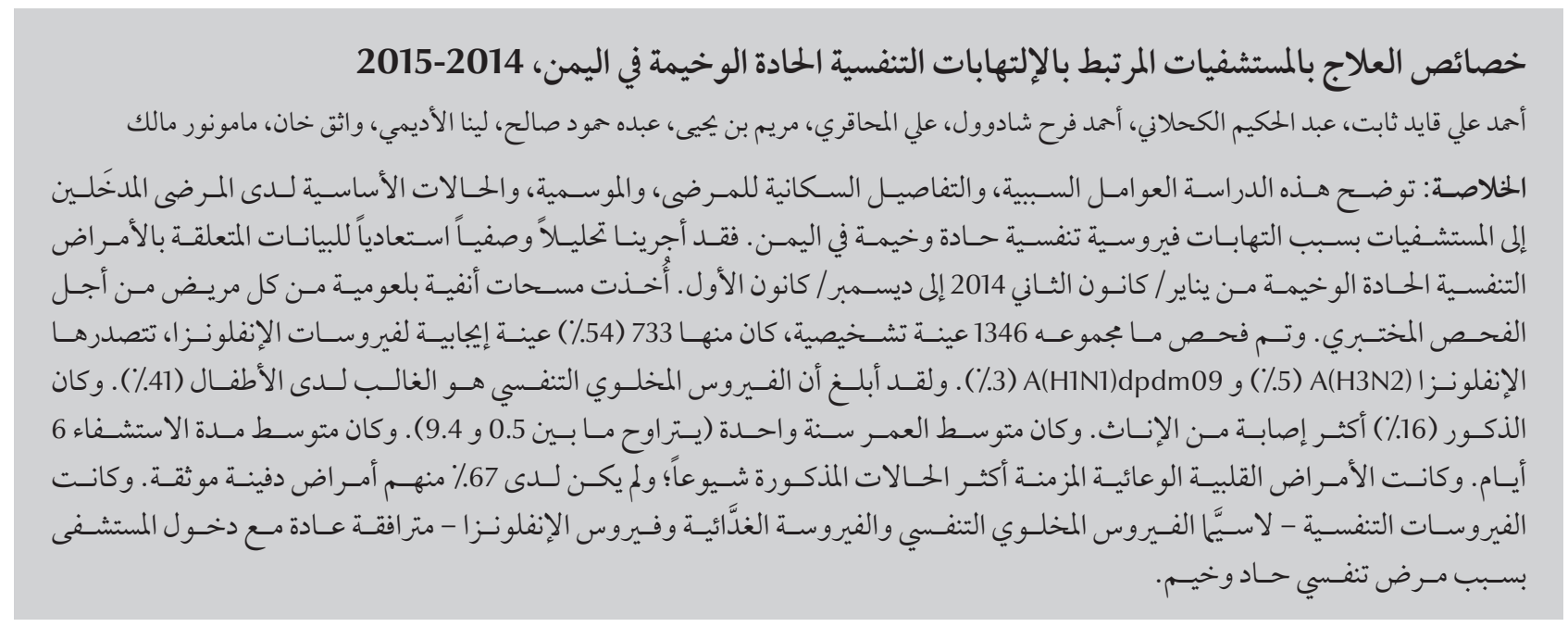

ABSTRACT This study aims to describe etiological agents, demographic details of patients, seasonality and underlying conditions among patients hospitalized due to viral severe acute respiratory infection (SARI) in Yemen. We carried out a retrospective descriptive analysis of data from January 2014 to December 2015. Nasopharyngeal swabs were taken from each patient for laboratory testing. A total of 1346 diagnostic specimens were tested, of which 733 (54\%) were positive for influenza viruses. Influenza $\mathrm{A}(\mathrm{H} 3)$ and $\mathrm{A}(\mathrm{H} 1 \mathrm{~N} 1)$ pdm09 predominated. Respiratory syncytial virus (RSV) was reported predominantly among children (41\%). Males (61\%) were more affected than females. The median age was 1 year (range 0.5-94.0). The median length of hospitalization was 6 days. Chronic cardiovascular disease was the most commonly reported underlying condition, but $67 \%$ had no documented underlying disease. Respiratory viruses, particularly RSV, adenovirus and influenza, were commonly associated with hospitalization for SARI.

Yémen : caractéristiques des cas d'hospitalisation associés aux infections respiratoires aiguës sévères, 2014-2015

RÉSUMÉ Cette étude présente les agents étiologiques, les données démographiques des patients, la saisonnalité et les pathologies sous-jacentes chez des patients hospitalisés en raison d'infections respiratoires aiguës sévères (IRAS) au Yémen. Nous avons réalisé une analyse descriptive rétrospective des données portant sur les IRAS et couvrant la période de janvier 2014 à décembre 2015. Des sécrétions rhinopharyngées ont été prélevées par écouvillonnage pour chaque patient afin d'être testées en laboratoire. Un total de 1346 échantillons diagnostiques ont été testés, parmi lesquels $733(54 \%)$ se sont avérés positifs aux virus de la grippe. Les virus de la grippe $\mathrm{A}(\mathrm{H} 3 \mathrm{~N} 2)(5 \%)$ et $\mathrm{A}(\mathrm{H} 1 \mathrm{~N} 1) p d m 09$ (3\%) étaient prédominants. Le virus respiratoire syncytial (VRS) a été observé principalement chez les enfants (41\%). Les sujets de sexe masculin étaient plus touchés (61\%) que les sujets de sexe féminin. L'âge médian était d'un an (intervalle : 0,5-94). La durée médiane d'hospitalisation était de 6 jours. Les maladies cardio-vasculaires chroniques constituaient la pathologie la plus fréquemment rapportée ; $67 \%$ ne présentaient aucune pathologie sous-jacente établie. Les cas d’hospitalisation étaient généralement associés à des virus respiratoires, en particulier au VRS, à l'adénovirus et à la grippe.

${ }^{1}$ Pandemic Influenza Preparedness. ${ }^{2}$ General Directorate Disease Surveillance and Control; ${ }^{3}$ WHO Country Office, Sana'a, Yemen (correspondence to: A.A.K.Thabet: thabet64@live.com). ${ }^{4}$ National Influenza Programme, Ministry of Public Health, Yemen. ${ }^{5}$ Pediatric Department, Al-Sadaqa

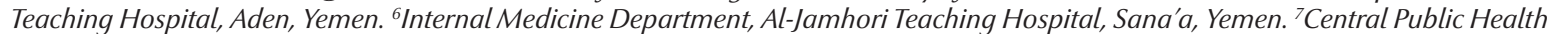
Laboratory, Sana'a, Yemen. ${ }^{8}$ WHO Regional Office for the Eastern Mediterranean, Cairo, Egypt.

Received: 24/04/16; accepted: 08/08/16 


\section{Introduction}

Seasonal influenza causes a substantial burden of illness worldwide, and infections can lead to severe illness that requires hospital care. Influenzaassociated hospitalization has been studied in many countries around the world (1-7). Such studies can reveal the pattern of severe illness, and can be used in guiding public health policies. Influenza can precipitate or exacerbate other respiratory and circulatory conditions, and there is a wide spectrum of clinical pathways and outcomes for influenza-associated conditions and complications (7-10). As laboratory testing of specimens and virological confirmation of influenza infection are not conducted for all patients nor for all deaths, estimates of hospitalizations for influenza cannot be based on reported episodes alone.

Influenza virus surveillance was introduced in Yemen in 2010 following the H1N1 outbreak, with 6 sentinel sites providing representation of the different geographical areas of the country. Yemen benefits from the Pandemic Influenza Preparedness Framework, a public health plan for increasing global preparedness to respond to pandemic influenza by improving influenza case detection and monitoring influenza epidemics and trends in circulating influenza viruses. Within this framework, a variety of data sources are used to obtain information on circulating influenza strains, the numbers of patients seen with influenza-like illness (ILI) or severe acute respiratory infection (SARI), sex, age group, timing of influenza activities, the number of specimens collected, the proportion of negative and positive samples and the types of influenza viruses. The influenza surveillance programme also monitors novel respiratory viruses.

Estimates of influenza-associated SARI incidence are usually limited to the area where surveillance is performed; however, there is regional variation in risk factors, epidemiology and health care-seeking practices which can affect the rates of hospitalization $(4,6,10)$. Virus transmission or clinical presentation of SARI may also be affected by differences in cultural practices, the environment, geography, human genetics and social structures. Although data on natural history, risk factors, severity and outcome are important to guide prioritization of prevention and control of SARI, such data are limited in developing countries, including Yemen $(2,4,8)$. We investigated the etiological agents, demographics of patients, seasonality and underlying conditions among patients hospitalized for SARI in Yemen in 2014-2015.

\section{Methods}

This study is based on analysis of all available data on SARI between January 2014 and December 2015 compiled by the Disease Control and Surveillance team. Surveillance focal points collect SARI data weekly in accordance with the WHO case definition from the surveillance sentinel sites in Aden and Sana'a. A case of SARI was defined as: acute respiratory infection with history of fever or measured fever of $\geq 38^{\circ} \mathrm{C}$, cough, onset within the previous 10 days and requiring hospitalization. The data were then reported at national level, where the surveillance coordinator and SARI data manager entered the data using an Excel sheet with a separate row for each patient.

We estimated the total number of consultations for all causes and the number of SARI cases in hospitals or health clinics by age group, sex distribution, date of onset, date of collecting samples and date of testing. Demographics (age, sex and nationality), laboratory findings, time course of the illness (admission and death) and underlying diseases were calculated for each case on a standard form. Trained health care workers extracted data from case notes.
Nasopharyngeal specimens were taken from each patient with a nasopharyngeal flocked swab (Copan, Italy) by experienced, trained staff. The swab was gently inserted into the nostril towards the pharynx until resistance was felt and then rotated 3 times to obtain epithelial cells. It was then withdrawn and placed into $2.5 \mathrm{~mL}$ of phosphatebuffered saline. The samples were transported on ice to the laboratory within a few hours of collection. They were then vortexed, transferred into $1.5-\mathrm{mL}$ Eppendorf tubes and kept at $-70{ }^{\circ} \mathrm{C}$ until tested at the Central Public Health laboratory in Sana' a. They were retested in a WHO collaborating centre, NAMRU- 3 in Cairo, for quality control. The diagnosis was confirmed by real-time reverse transcription polymerase chain reaction.

\section{Statistical analysis}

Frequency tables were used for data presentation. Associations were considered statistically significant at $\mathrm{P}<0.05$ in the chi-squared test. Data were analysed with SPSS for Windows, version 13.0.

\section{Ethical considerations}

Informed consent, which is a routine part of SARI/ILI system, was obtained adult patients from and parents; a child was recruited into the study only after the guardian or parents had consented. Institutional review boards in the Ministry of Public Health and Population in Yemen approved the study protocol.

\section{Results}

During 2014-2015, 1346 diagnostic specimens were tested for respiratory viruses, of which 733 (54\%) were positive for viruses. Of the positive cases, respiratory syncytial virus (mean $41.0 \%$ ) adenoviruses (mean 17.5\%) and influenza viruses (mean 10.0\%) were reported mostly (Figure 1). Coinfection with multiple viruses occurred in $18 \%$. 


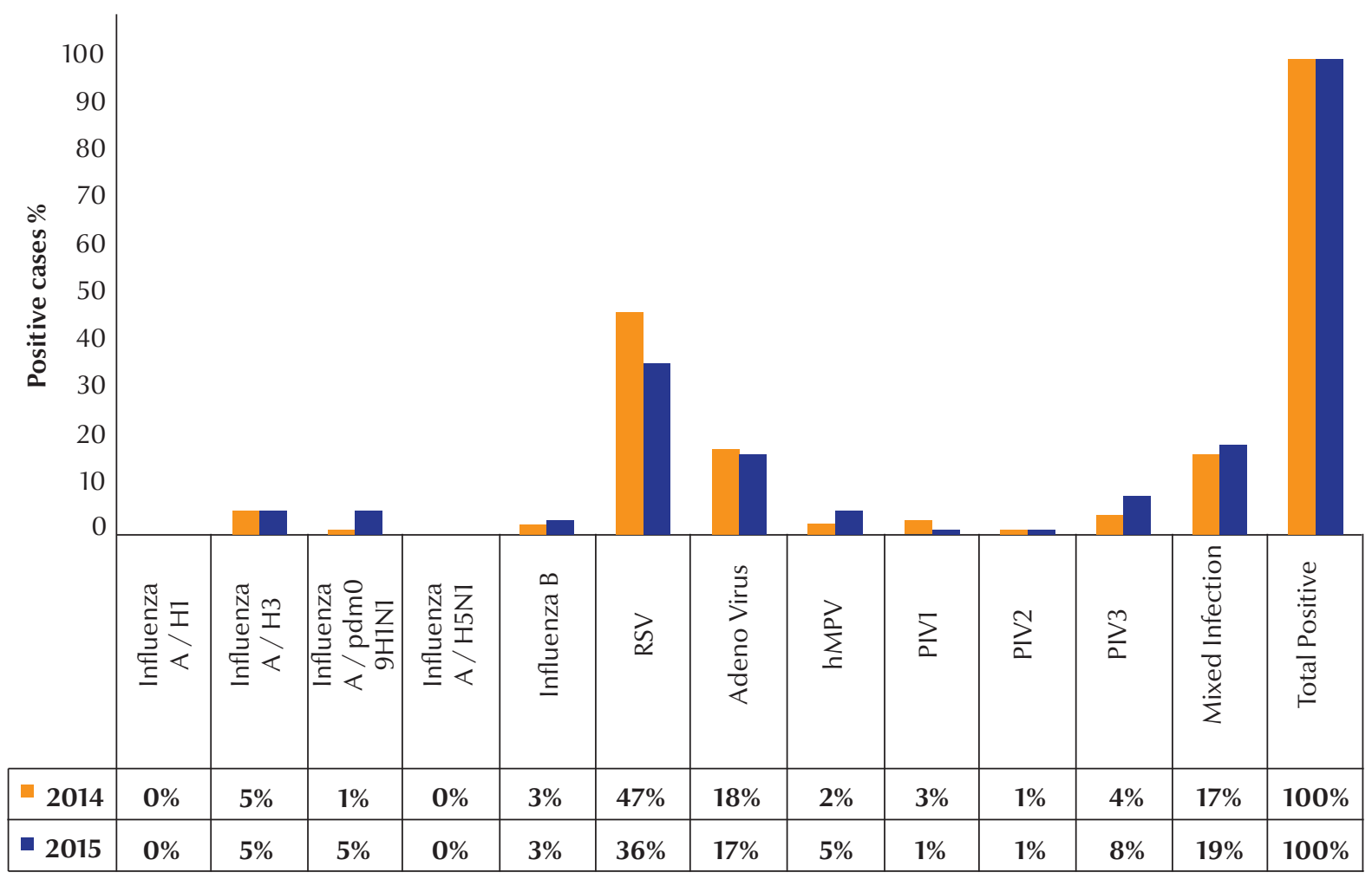

Type of pathogen detected in specimens from SARI patients

Figure 1 Distribution of cases admitted to hospital with severe acute respiratory infection (SARI) according to virus type, Yemen, 2014-2015 (RSV = respiratory syncytial virus)

Of the 1346 patients hospitalized with SARI, 826 (61\%) were male. The median age was 1 year) (Table 1 ). Out of 733 patients testing positive for viruses, 534 (73\%) required oxygen therapy, while 378 required intensive care; of these, 25 (7\%) died, mainly among the younger and older age groups (Table 2).
Disease activity due to respiratory viruses was present throughout the year, with peaks throughout November 2014 to February 2015, June-August 2015 and October-December 2015 (Figure 2).

Chronic cardiovascular disease was the most commonly reported underlying condition (Table 3). No documented underlying disease was found in $67 \%$ of patients. Underlying disease was equally distributed by sex but not by age, with few of those aged under 15 years having any underlying condition (Table 4).

\section{Discussion}

The most frequent viral pathogen in patients with SARI was RSV, followed by

\begin{tabular}{|c|c|c|}
\hline Characteristic & \multicolumn{2}{|c|}{ Value } \\
\hline Median age (years) & \multicolumn{2}{|c|}{1.0 (range $0.5-94.0$ ) } \\
\hline Median duration of hospitalization (days) & \multicolumn{2}{|c|}{6 (range 9-52) } \\
\hline \multirow[t]{2}{*}{ Median time from onset of symptoms to hospital admission (days) } & \multicolumn{2}{|c|}{2} \\
\hline & No. & $\%$ \\
\hline Number of patients admitted to hospital with SARI & 1346 & - \\
\hline Males & 826 & 61 \\
\hline Number testing positive for viruses & 733 & 54 \\
\hline Patients testing positive who required intensive care & 378 & 52 \\
\hline Mortality among SARI patients who required intensive care & 25 & 7 \\
\hline Patients testing positive who required oxygen therapy & 534 & 73 \\
\hline
\end{tabular}




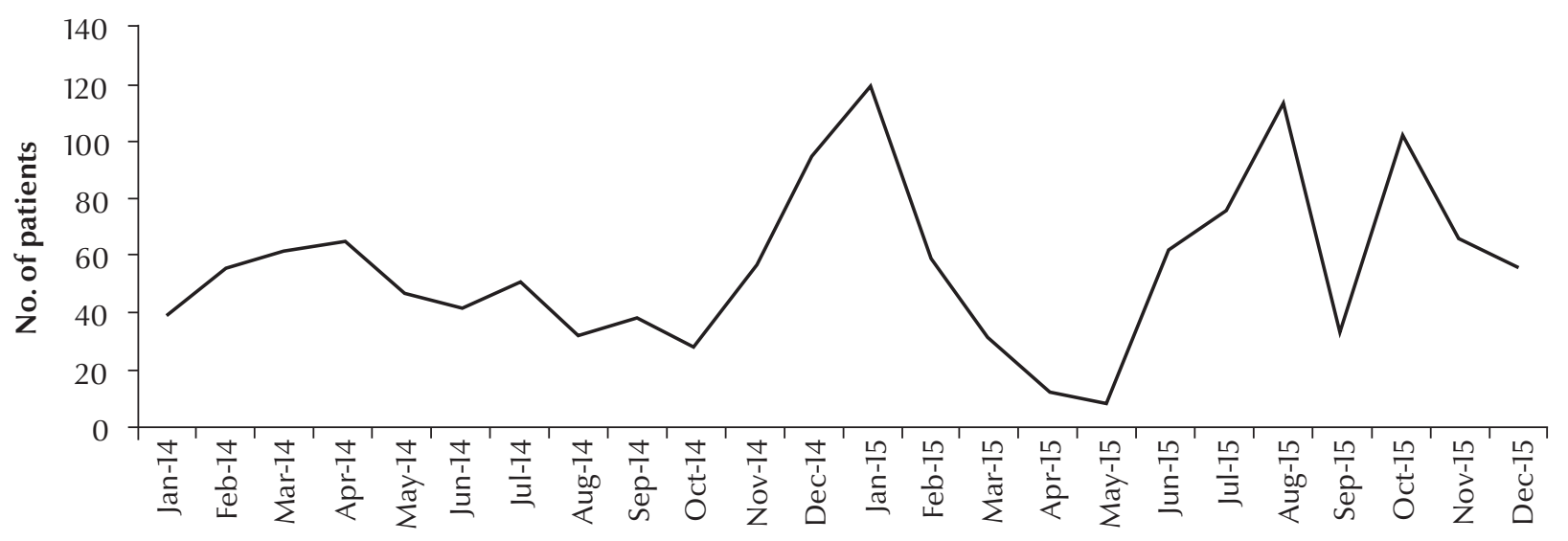

Time of enrolment

Figure 2 Distribution of patients admitted to hospital with severe acute respiratory infection (SARI), Yemen, 2014-2015

adenovirus and influenza viruses $\mathrm{H} 3 \mathrm{~N} 2$ and $\mathrm{H} 1 \mathrm{~N} 1$, as found in a number of other studies (1-3,6,7,10). Most of the SARI patients admitted to hospital were males and young children, as found in studies by Meerhoff et al. (6) and Khor et al. (7). An additional factor in our study might be that women in Yemen are usually veiled, which may further protect them against infection (8). The median duration of hospitalization of patients with SARI was 6 days (range, 9-52 days); this is in agreement with the findings of studies in Ghana (1), Eastern Europe (6), Saudi Arabia (2) and the United Arab Emirates (3). Patients with SARI who tested positive for influenza virus generally required oxygen therapy more often than the influenza-negative SARI patients, as reported elsewhere (9-12).

In this study, infection with SARI occurred throughout the year, as in the United Arab Emirates (3), while in India, viral respiratory infections were more frequent in the autumn and winter: increasing during the rainy season in July and August and continuing at a lower level throughout the year (4,12-14).

Cardiacdiseases were the mostcommon comorbidity for hospitalized SARI patients in this study. This is in contrast to the findings of Meerhoffet al. (6) and
Coffin et al. (9), who reported that cardiac, neurological and neuromuscular diseases were independent risk factors for prolonged hospitalization among

children with laboratory-confirmed influenza; it also contrasts with the findings of Bellau-Pujol et al. (15) and Iwane et al. (16), perhaps because of

\begin{tabular}{|c|c|c|}
\hline \multirow[t]{2}{*}{ Age (years) } & \multicolumn{2}{|c|}{ Deaths due to SARI } \\
\hline & No. & $\%$ \\
\hline $0-1$ & 2 & 8 \\
\hline $2-4$ & 5 & 20 \\
\hline 5-14 & 7 & 28 \\
\hline $15-49$ & 2 & 8 \\
\hline $50-64$ & 6 & 24 \\
\hline$>65$ & 3 & 12 \\
\hline Total & 25 & 100 \\
\hline
\end{tabular}

Table 3 Distribution of underlying diseases in patients admitted to hospital in Yemen with severe acute respiratory infection during 2014 and 2015

\begin{tabular}{lcc} 
Underlying & Patients & \\
disease & No. & $\%$ \\
None & 908 & 67 \\
Cardiovascular disease & 173 & 13 \\
Neurological disease & 78 & 6 \\
Bronchial asthma & 47 & 3 \\
Endocrine disease & 47 & 3 \\
Haematological disease & 24 & 2 \\
Renal disease & 23 & 2 \\
Chronic obstructive pulmonary disease & 21 & 2 \\
Tuberculosis & 13 & 1 \\
Hepatic disease & 12 & 1 \\
Total & 1346 & 100 \\
\hline
\end{tabular}




\begin{tabular}{|c|c|c|c|c|c|c|c|c|}
\hline \multirow{2}{*}{ Underlying condition } & \multicolumn{6}{|c|}{ Age (years) } & \multicolumn{2}{|c|}{ Total } \\
\hline & $0-1$ & $2-4$ & $5-14$ & $15-49$ & $50-64$ & $>65$ & No. & $\%$ \\
\hline Cardiovascular disease & 0 & 6 & 12 & 36 & 44 & 75 & 173 & 13 \\
\hline Neurological disease & 0 & 0 & 0 & 8 & 18 & 52 & 78 & 6 \\
\hline Bronchial asthma & 0 & 0 & 1 & 17 & 22 & 7 & 47 & 3 \\
\hline Endocrine disease & 0 & 0 & 0 & 9 & 22 & 16 & 47 & 3 \\
\hline Haematological disease & 0 & 1 & 1 & 5 & 11 & 6 & 24 & 2 \\
\hline Renal disease & 0 & 0 & 0 & 4 & 8 & 11 & 23 & 2 \\
\hline Chronic obstructive pulmonary disease & 0 & 0 & 0 & 4 & 9 & 8 & 21 & 2 \\
\hline Tuberculosis & 0 & 0 & 0 & 5 & 5 & 3 & 13 & 1 \\
\hline Hepatic disease & 0 & 0 & 2 & 5 & 3 & 2 & 12 & 1 \\
\hline
\end{tabular}

differences in geography, etiological agents or diagnostic methods rather than study design or methodology.

This is first study describing the characteristics of SARI-associated hospitalization in Yemen; our findings will contribute to increasing the evidence base available to public health policy-makers in the country.

\section{Acknowledgements}

The authors thank all the surveillance staff, physicians, nurses and health care workers in the SARI and ILI sentinel sites, intensive care units, the Central Public Health Laboratory and NAMRU3 for detecting, reporting, observing and testing all influenza cases.

\section{Funding: None.}

Competing interests: None declared.

\section{References}

1. Kwofie TB, Anane YA, Nkrumah B, Annan A, Nguah SB, Owusu $M$. Respiratory viruses in children hospitalized for acute lower respiratory tract infection in Ghana. Virol J. 2012;9:78.

2. Al-Shehri MA, Sadeq A, Quli K. Bronchiolitis in Abha, Southwest Saudi Arabia: viral etiology and predictors for hospital admission. West Afr J Med. 2005;24: 299-304.

3. Uduman SA, Ijaz Mk, Kochiyil J, Mathew T, Hussam MK. Respiratory syncytial virus infection among hospitalized young children with acute lower respiratory illnesses in AI Ain, UAE. J Comm Dis. 1996;28:245-52.

4. Broor S, Parveen S, Bharaj P, Prasad VS, Srinivasulu KN, Sumanth KM et al. A prospective three-year cohort study of the epidemiology and virology of acute respiratory infections of children in rural India. PLoS ONE. 2007;2:e491.

5. Black RE, Cousens S, Johnson HL, Lawn JE, Rudan I, Bassani DG et al. Global, regional, and national causes of child mortality in 2008: a systematic analysis. Lancet. 2010;375(9730):1969-87.

6. Meerhoff TJ, Mosnier A, Schellevis F, Paget WJ, EISS RSV Task Group. Progress in the surveillance of respiratory syncytial virus (RSV) in Europe: 2001-2008. Euro Surveill. 2009;14(40):pii $=19346$.

7. Khor CS, Sam C, Hooi PS, Quek KF, Chan YF. Epidemiology and seasonality of respiratory viral infections in hospitalized children in Kuala Lumpur, Malaysia: a retrospective study of 27 years. BMC Pediatrics. 2012;12:32.

8. Thabet AAK, Moulhee NM, Al-kohlani A, Jahaf M. Epidemiology of fatal cases associated with pandemic influenza reported in Yemen. Natural Science. 2012;4(11):803-7 (http://dx.doi. org/10.4236/ns.2012.411107).
9. Coffin SE, Zaoutis TE, Rosenquist ABW, Heydon K, Herrera G, Bridges CB et al. Incidence, complications, and risk factors for prolonged stay in children hospitalized with communityacquired influenza. Pediatrics. 2007;119:740.

10. Fattouh AM, Mansi YA, El-anany MG, El-Kholy AA, El-Karaksy $\mathrm{HM}$. Acute lower respiratory tract infection due to respiratory syncytial virus in a group of Egyptian children under 5 years of age. Ital J Pediatr. 2011;37:14.

11. Tregoning JS, Schwarze J. Respiratory viral infections in infants: causes, clinical symptoms, virology, and immunology. Clin Microbiol Rev. 2010; 23:74-98.

12. Yusuf S, Piedimonte G, Auais A, Demmler G, Krishnan S, Van Caeseele $\mathrm{P}$ et al. The relationship of meteorological conditions to the epidemic activity of respiratory syncytial virus. Epidemiol Infect. 2007;135:1077-90.

13. Loh TP, Lai FY, Tan ES, Thoon KC, Tee NW, Cutter J et al. Correlations between clinical illness, respiratory virus infections and climate factors in a tropical paediatric population. Epidemiol Infect. 2011;139:1884-94.

14. Lofgren E, Fefferman NH, Naumov YN, Gorski J, Naumova EN. Influenza seasonality: underlying causes and modeling theories. J Virol. 2007, 81:5429-36.

15. Bellau-Pujol S, Vabret A, Legrand L, Dina J, Gouarin S, Petitjean-Lecherbonnier J et al. Development of three multiplex RT-PCR assays for the detection of 12 respiratory RNA viruses. J Virol Methods. 2005;126(1-2):53-63.

16. Iwane MK, Edwards KM, Szilagyi PG, Walker FJ, Griffin MR, Weinberg GA et al: Population-based surveillance for hospitalizations associated with respiratory syncytial virus, influenza virus, and parainfluenza viruses among young children. Pediatrics. 2004;113(6):1758-64. 